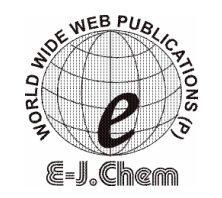

http://www.e-journals.net
ISSN: 0973-4945; CODEN ECJHAO

E-Journal of Chemistry

Vol. 5, No. 1, pp. 136-143, January 2008

\title{
Theoretical Studies of Some Fluoro Compounds with Silicon, Phosphorus and Sulphur and Establishment of Negative Hyperconjugation through Calculation of Charge
}

\author{
P K MOHAMED IMRAN and K SUBRAMANI \\ Department of Chemistry, Islamiah College, \\ Vaniyambadi, TN, India - 635752 \\ imranpk@fastmail.us
}

Received 1 July 2007; Revised 21 August 2007; Accepted 13 September 2007

\begin{abstract}
Hyperconjugation is an act to build $\pi$ bond character into bonds that have only $\sigma$ character. Negative Hyperconjugation is the flow or movements of electrons from $\pi$ to $\sigma^{*}$ orbitals and more particularly from $\pi$ orbital of a carbon atom to the $\sigma^{*}$ orbital of the $\mathrm{C}-\mathrm{X}$ bond, where $\mathrm{X}$ is any electronegative atom. This effect is different from Inductive effects. An attempt is made to study the negative hyperconjugation (Anomeric Effect) by the calculation of the charges at the Density Functional Theory (DFT) level for some compounds with hypervalent atoms like Si, $\mathrm{P} \& \mathrm{~S}$
\end{abstract}

Keywords: DFT, Negative Hyperconjugation, Hypervalent atoms

\section{Introduction}

The effect of donation of electron density from filled $\pi$ or $n_{\pi}$ orbitals of the symmetry adapted $\sigma^{*}$ orbital(s) of the $\sigma$ bond(s) of a molecular entity resulting in building $\pi$ character into bonds that nominally posses only $\sigma$ character is termed anomeric effect. The consequences of the effect are, for example, elongation of the C-F bond in the $\beta$-fluoro ethyl anion and the stabilization of antiperiplanar conformation of fluoromethylamine ${ }^{1}$. In short negative hyperconjugation is $\pi$ or $n_{\pi} \rightarrow \sigma^{*}$ as shown in the below scheme 1 .

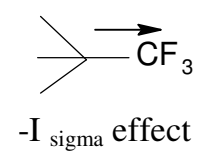

$-\mathrm{I}_{\text {sigma }}$ effect<smiles>CC1=C(C)CC[C-]1</smiles>

$-\mathrm{I}_{\mathrm{pi}}$ effect

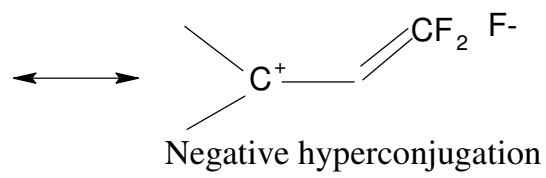

Scheme 1. 
Some of the important consequences of the negative hyperconjugation are

(i) The shortening of the AY bond in $X_{n} A Y$, where $\mathrm{X}$ is an electronegative element, $\mathrm{A}$ is any hypervalent atom and $\mathrm{Y}$ is any other atom or group attached to $\mathrm{A}$.

(ii) The increase in $\pi$ orbital population of the $\mathrm{X}$ atom and thereby a change in the charge on that atom

(iii) Widening of the XAY angle, for example, 113 degrees in the place of tetrahedral angle

(iv) Lengthening of the AX bond.

Hyperconjugation of the $\mathrm{C}-\mathrm{X}$ bond is maximum when the dihedral angle between the $\pi$-orbital of $\mathrm{X}$ atom and the orbital of a $\pi$ system or of the same symmetry from which electrons flow, is either zero degree or 180 degree and falls to zero when the dihedral angle is 90 degree $^{2}$.

The presence of fluorine atoms gives rise also to inductive effect which is felt through the $\sigma$ bonds and the polarization is not be confused with negative hyperconjugation. To measure the inductive effects separately, the dihedral angles around the atoms responsible for negative hyperconjugation was set to 90 degree during optimization, when at this angle anomeric effect is minimized to zero ${ }^{3}$.

The concept of bond order, bond order-bond energy relations and the Pauling relationship between bond length and bond order is quite helpful in verifying the changes in the bond length ${ }^{4}$. The shortening of the $\mathrm{C}-\mathrm{X}$ bond and the lengthening of the $\mathrm{A}-\mathrm{X}$ bond can be easily verified using these rules. The imposition of symmetry during geometry optimisation is useful in calculating the distribution of the charges both on the $\pi$ or $\sigma$ centers. If the substituent is phenyl ring, it can be confined to a plane to achieve the dihedral angle required for the overlap by the $\pi$ orbitals of the aromatic ring and the orbitals of the same symmetry found in the hypervalent atom and the halides. The gross orbital population (GOP) is required for the calculation of the charges on the $\sigma$ or $\pi$ centers.

Phosphorus, sulphur and silicon were primarily studied for the anomeric effect (the effect due to negative hyperconjugation) with highly electronegative atom like fluorine. For comparison some imaginary systems without the ring or without the electronegative atoms were also included. All the possible symmetries were tried during geometry optimization and the geometry that had the lowest heat of formation was considered stable. Based on this the anomeric effect was studied. The contribution of the $n$-electrons of the fluorine atoms was also established.

\section{Experimental}

\section{Computational Methods}

The systems $\mathrm{C}_{6} \mathrm{H}_{5}-\mathrm{A}$, where $\mathrm{A}=\mathrm{PF}_{4}, \mathrm{SiF}_{3}$ and $\mathrm{SF}_{5}$ were optimized and characterized using the Density Functional Theory method, B3LYP with a 6-31 G* basis set. For comparison of the results, the calculations were also performed for $\mathrm{C}_{6} \mathrm{H}_{5}-\mathrm{N}$, where $\mathrm{N}=\mathrm{CH}_{3}$ and $\mathrm{CF}_{3}$ at the same level of theory. The frequency calculations indicated that all the systems were minima and there was no imaginary frequency at all to suggest any transition state.

All the calculations were done using Gaussian 98 on IBMS12 machine. For optimization the geometrical parameters were allowed to vary within the given symmetry point group. The total charges and the $\sigma$ and the $\pi$ charges were also calculated separately from the orbital population values ${ }^{5}$. 


\section{Results and Discussion}

\section{Phenyltrifluorosilane}

The structure Ia was first optimized using the DFT method at the 6-31G* level under $\mathrm{C}_{2 \mathrm{v}}$ symmetry. Given the freedom to rotate at the $\mathrm{Si}-\mathrm{C}$ axis the molecule attained $\mathrm{C}_{\mathrm{s}}$ symmetry. This was further supported by lower heat of formation. Due to unfavourable overlap from the $\pi$-system (phenyl ring) with $\sigma^{*}$ orbitals of fluorine atoms, the bond length was lengthened followed by an increase in tetrahedral angle. There was also an increase in the $\pi$ charge on one of the three fluorine atoms. Only one of these three fluorine atoms effectively showed the presence of negative hyperconjugation. This may be due to the symmetry of the molecule, particularly with the respect to the non-bonding electrons of the $\mathrm{F}$ atoms and the $\mathrm{P}_{\mathrm{z}}$ orbitals of the phenyl ring. In the $\mathrm{C}_{\mathrm{s}}$ symmetry (Ib), only one of the $\mathrm{F}$ atoms had a dihedral angle of 0 degrees with respect to the $\mathrm{C}$-atom pi orbital of the phenyl ring (the ipso $\mathrm{C}$-atom). Only at this value the effect would be maximum. The other two $\mathrm{F}$ atoms did not have sufficient dihedral angle (Ic) to show negative hyperconjugation. Hence these two atoms did not show the effect to the extent the $\mathrm{F}_{1}$ atom showed.

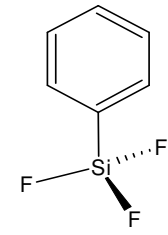

Ia $\left(\mathrm{C}_{2 \mathrm{v}}\right)$

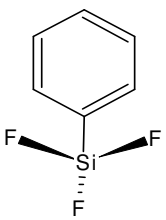

Ib $\left(\mathrm{C}_{\mathrm{s}}\right)$

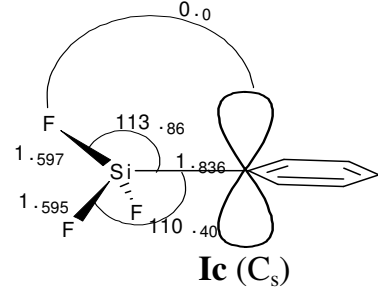

Ic $\left(\mathrm{C}_{\mathrm{s}}\right)$

Structure of phenyltrifluorosilane under two symmetries $(\mathbf{1 a} \& \mathbf{1 b})$ and the calculated angles and dihedral angles (1c)

All the increased factors, like the bond length and the bond angle (shown in Table 1) point to the Anomeric effect. Due to charge withdrawal by electronegative substituents, there should be effective shrinkage of the C-Si bond length. This has been found to be true, as the theoretical value, $1.888 \mathrm{~A}^{\circ}$, was found using an imaginary system without an $\mathrm{F}$ or $\pi$ system, $\mathrm{CH}_{3} \mathrm{SiH}_{3}$. This might be of greater importance for $d$-orbitals of second row atoms as opposed to first row atoms, since $d$ - functions generally lead to much greater bond length contractions in the case of hypervalent as opposed to normal valent second row compounds ${ }^{6}$.

This shortening of bond length was enough to prove that there is a drain of $\pi$ electrons from the ring and the withdrawal of $\pi$ electrons to the $\sigma^{*}$ orbitals of the $\mathrm{F}$ atom through the hypervalent atom $\mathrm{Si}$. The role of this atom is to provide " $d$-orbitals" for effective overlapping. This was further evidenced by the fact that the gross orbital population ( $\pi$ orbital values obtained as a sum of $2 p_{z}=3 p_{z}+4 z z+4 x z+4 y z$ ) for the $F$ atom undergoing the anomeric affect was found to have a higher value compared to the other two $\mathrm{F}$ atoms (Table 2).

The other effect like inductive effect would be competing with this, but from the above data it was enough to conclude that negative hyperconjugation should be supported by decrease in $\mathrm{C}-\mathrm{Si}$ bond length, increase in $\mathrm{Si}-\mathrm{F}$ bond length along with (or without) increase in $\mathrm{C}-\mathrm{Si}-\mathrm{F}$ bond angle and increase in $\pi$ orbital population number of fluorine atom. Of these three $\mathrm{F}$ atoms only one was more favored for the Anomeric effect due to its geometric position. 
Table 1. The geometrical parameters and stabilization energies of various systems obtained by DFT 6-31 G* MO calculations.

\begin{tabular}{|c|c|c|c|c|c|}
\hline Structure & $\begin{array}{c}\text { System } \\
\text { (symmetry) }\end{array}$ & $\begin{array}{l}\mathrm{A}-\mathrm{X} \\
\mathrm{A}^{\mathrm{o}}\end{array}$ & $\begin{array}{c}A-Y \\
A^{o}\end{array}$ & $\begin{array}{l}<X A Y, \\
\text { degree }\end{array}$ & $\begin{array}{l}\Delta \mathrm{E}, \\
\text { Kcal }\end{array}$ \\
\hline I & $\begin{array}{c}\mathrm{C}_{6} \mathrm{H}_{5}-\mathrm{SiF}_{3} \\
\left(\mathrm{C}_{\mathrm{S}}\right)\end{array}$ & $\begin{array}{l}\mathrm{F}_{1}=1.597 \\
\mathrm{~F}_{2}=1.595 \\
\mathrm{~F}_{3}=1.595\end{array}$ & 1.836 & $\begin{array}{l}113.86 \\
110.40 \\
110.40\end{array}$ & -1.3081 \\
\hline II & $\begin{array}{c}\mathrm{C}_{6} \mathrm{H}_{5}-\mathrm{CF}_{3} \\
\left(\mathrm{C}_{\mathrm{S}}\right)\end{array}$ & $\begin{array}{l}\mathrm{F}_{1}=1.354 \\
\mathrm{~F}_{2}=1.352 \\
\mathrm{~F}_{3}=1.352\end{array}$ & $1.889^{1}$ & $\begin{array}{l}111.8 \\
111.9 \\
111.9\end{array}$ & -0.9072 \\
\hline III & $\begin{array}{c}\mathrm{C}_{6} \mathrm{H}_{5}-\mathrm{CH}_{3} \\
\left(\mathrm{C}_{\mathrm{S}}\right)\end{array}$ & $\begin{array}{l}\mathrm{H}_{1}=1.098 \\
\mathrm{H}_{2}=1.095 \\
\mathrm{H}_{3}=1.095\end{array}$ & $1.513^{2}$ & $\begin{array}{l}111.3 \\
111.5 \\
111.5\end{array}$ & -0.4320 \\
\hline IV & $\begin{array}{c}\mathrm{C}_{6} \mathrm{H}_{5}-\mathrm{PF}_{4} \\
\left(\mathrm{C}_{2} \mathrm{~V}\right)\end{array}$ & $\begin{array}{l}\mathrm{F}_{1}=1.640 \\
\mathrm{~F}_{2}=1.640 \\
\mathrm{~F}_{3}=1.310 \\
\mathrm{~F}_{4}=1.310\end{array}$ & 1.746 & $\begin{array}{c}93.57 \\
93.57 \\
115.12 \\
115.12\end{array}$ & -1.5496 \\
\hline V & $\begin{array}{c}\mathrm{CH}_{3}-\mathrm{PF}_{4} \\
\left(\mathrm{C}_{2} \mathrm{~V}\right)\end{array}$ & $\begin{array}{l}\mathrm{F}_{1}=1.492 \\
\mathrm{~F}_{2}=1.492 \\
\mathrm{~F}_{3}=1.428 \\
\mathrm{~F}_{4}=1.428\end{array}$ & 1.869 & $\begin{array}{c}90.6 \\
90.6 \\
123.6 \\
123.6\end{array}$ & -0.6113 \\
\hline VI & $\begin{array}{c}\mathrm{C}_{6} \mathrm{H}_{5}-\mathrm{SF}_{5} \\
\left(\mathrm{C}_{2} \mathrm{~V}\right)\end{array}$ & $\begin{array}{l}\mathrm{F}_{1}=1.623 \\
\mathrm{~F}_{2}=1.630 \\
\mathrm{~F}_{3}=1.630 \\
\mathrm{~F}_{4}=1.630 \\
\mathrm{~F}_{5}=1.630\end{array}$ & 1.825 & $\begin{array}{c}180.0 \\
90.0 \\
90.0 \\
90.0 \\
90.0\end{array}$ & -1.7990 \\
\hline VII & $\begin{array}{c}\mathrm{CH}_{3}-\mathrm{SH}_{5} \\
(\mathrm{Cs})\end{array}$ & $\begin{array}{l}\mathrm{H}_{1}=1.415 \\
\mathrm{H}_{2}=1.431 \\
\mathrm{H}_{3}=1.431 \\
\mathrm{H}_{4}=1.431 \\
\mathrm{H}_{5}=1.431\end{array}$ & 1.896 & $\begin{array}{c}180.0 \\
90.0 \\
90.0 \\
90.0 \\
90.0 \\
\end{array}$ & -0.7025 \\
\hline
\end{tabular}

$A-X$ refers to the bond length between a hypervalent atom and an electronegative atom and $A-Y$ to bond length between hypervalent atom and the Carbon atom

${ }^{1}$ The ipso $C-C\left(F_{3}\right)$ distance, ${ }^{2}$ The ipso $C-C\left(H_{3}\right)$ distance

All the values given above were obtained using 6-31 G* basis sets. The point groups represented in parentheses are for the optimized geometry with lower $\Delta E$ values.

To measure the effect of hypervalent atoms, a study was made with another system without the $\mathrm{Si}$ atom, $\mathrm{C}_{6} \mathrm{H}_{5} \mathrm{CF}_{3}$, II. It was found that there was a decrease in the $\mathrm{C}-\mathrm{F}$ bond length of $\mathrm{F}$ atoms $2 \& 3$. But due to the absence of hypervalent atom the effect of negative hyperconjugation was not felt by a significant decrease in change of bond angle. Hence in such systems, it can be concluded that the effect has to be followed up by change in bond angles involved. To sum up, the effect would be more enhanced in the presence of hypervalent atom like silicon and with a favourable angle for overlapping. 


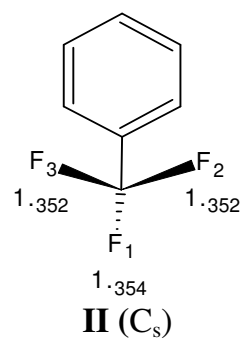

Trifluoromethylbenzene and the bond lengths in angstroms

In the absence of silicon atom, the inductive effect would compete with Anomeric effect and this could be recognized by calculating the $\sigma$ and $\pi$ charges $^{7}$. The negative hyperconjugation was present in this case even in the absence of silicon atom, but without any marked change in the geometry of the molecule.

Table 2. The Gross orbital population number ( $p i$ orbital electron number) of the different systems obtained by DFT 6-31 G* MO calculations at the B3LYP level and the pi charges at the ipso carbon atom.

\begin{tabular}{|c|c|c|c|c|}
\hline Structure & $\begin{array}{c}\text { System } \\
\text { (symmetry) }\end{array}$ & $\begin{array}{l}\text { Gross Orbital } \\
\text { Population }\end{array}$ & $\begin{array}{l}P i \text { - charges } \\
\text { on the ipso } \mathrm{C}\end{array}$ & $\begin{array}{c}\text { Sigma charges } \\
\text { on the ipso C }\end{array}$ \\
\hline I & $\begin{array}{c}\mathrm{C}_{6} \mathrm{H}_{5}-\mathrm{SiF}_{3} \\
\left(\mathrm{C}_{\mathrm{S}}\right)\end{array}$ & $\begin{array}{l}\mathrm{F}_{1}=1.895 \\
\mathrm{~F}_{2}=1.765 \\
\mathrm{~F}_{3}=1.765\end{array}$ & 0.085 & -0.164 \\
\hline II & $\begin{array}{c}\mathrm{C}_{6} \mathrm{H}_{5}-\mathrm{CF}_{3} \\
\left(\mathrm{C}_{\mathrm{S}}\right)\end{array}$ & $\begin{array}{l}F_{1}=1.906 \\
F_{2}=1.665 \\
F_{3}=1.665\end{array}$ & 0.106 & -0.113 \\
\hline III & $\begin{array}{c}\mathrm{C}_{6} \mathrm{H}_{5}-\mathrm{CH}_{3} \\
\left(\mathrm{C}_{\mathrm{S}}\right)\end{array}$ & & 0.118 & 0.057 \\
\hline IV & $\begin{array}{c}\mathrm{C}_{6} \mathrm{H}_{5}-\mathrm{PF}_{4} \\
\left(\mathrm{C}_{2} \mathrm{~V}\right)\end{array}$ & $\begin{array}{l}\mathrm{F}_{1}=1.928 \\
\mathrm{~F}_{2}=1.928 \\
\mathrm{~F}_{3}=1.794 \\
\mathrm{~F}_{4}=1.794\end{array}$ & 0.113 & -0.148 \\
\hline VI & $\begin{array}{c}\mathrm{C}_{6} \mathrm{H}_{5}-\mathrm{SF}_{5} \\
\left(\mathrm{C}_{2} \mathrm{~V}\right)\end{array}$ & $\begin{array}{l}\mathrm{F}_{1}=1.507 \\
\mathrm{~F}_{2}=1.937 \\
\mathrm{~F}_{3}=1.937 \\
\mathrm{~F}_{4}=1.937 \\
\mathrm{~F}_{5}=1.937\end{array}$ & 0.145 & -0.288 \\
\hline VII & $\begin{array}{c}\mathrm{C}_{6} \mathrm{H}_{5}-\mathrm{NO}_{2} \\
(\mathrm{Cs})\end{array}$ & & 0.302 & -0.031 \\
\hline VIII & $\mathrm{C}_{6} \mathrm{H}_{6}\left(\mathrm{~S}_{6}\right)$ & & 0.000 & -0.128 \\
\hline
\end{tabular}

\section{Phenyltetrafluorophosphorane}

Some possible structures for the system $\mathrm{C}_{6} \mathrm{H}_{5} \mathrm{PF}_{4}$ under symmetry considerations are given as per the structures IV a, b \& c. Given the freedom to rotate at the phosphorus atom, during optimization, the system assumed IVa structure. The heat of formation values also showed that this structure was stable compared to the other two, IV b \& c. The bond lengths and bond angles are tabulated in Table 1. There was an increase in $\mathrm{P}-\mathrm{F}$ bond length 
(from 1.31 to 1.64$)$ followed by an increase in the CPF angle $\left(90^{\circ}\right.$ as per the $\mathrm{C}_{2 \mathrm{~V}}$ symmetry before optimization) which indicated the presence of anomeric effect. There is also the shortening of the $\mathrm{C}-\mathrm{P}$ bond and a system without $\pi$ electrons and $\mathrm{F}$ atoms viz. $\mathrm{CH}_{3} \mathrm{PH}_{4}$ was studied using the same parameters and the bond lengths were also tabulated. It was found that the $\mathrm{C}-\mathrm{P}$ bond decreased from 1.869 to $1.746 \mathrm{~A}^{\mathrm{o}}$ when moving from an alkyl system to an aromatic system. This was indicative of the fact that there is a built up of $\pi$ character into the $\sigma^{*}$ bonds of the molecule and hence the shortening of the bond length.<smiles>FP(F)(F)(F)c1ccccc1</smiles>

IV a $\left(\mathbf{C}_{2 \mathbf{v}}\right)$<smiles>F[P-](F)(F)(F)(F)c1ccccc1</smiles>

IV b $\left(\mathbf{C}_{\mathrm{s}}\right)$<smiles>FP(F)(F)(F)c1ccccc1</smiles>

IV c $\left(\mathbf{C}_{3}\right)$

Structure of Phenyltetrafluorophosphorane under different symmetries

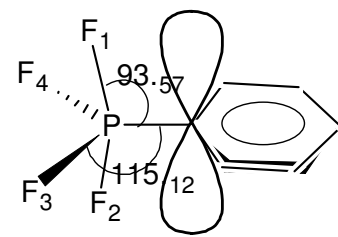

IV d<smiles></smiles>

IV e

Structures of Phenyltetrafluorophosphorane showing deviation in bond angles from $90^{\circ}$ (IV d) and Gross Orbital Population (IV e)

Moreover, the $\mathrm{F}$ atoms $1 \& 2$ alone are at a dihedral angle 0 or 180 degree with respect to the $\pi$ orbitals of the phenyl ring (the ipso $\mathrm{C}$ atoms IV d) and hence show more negative hyperconjugation compared with the rest of the two $\mathrm{F}$ atoms, which are in the plane of the phenyl ring and hence have a dihedral angle of $90^{\circ}$ - where the effect is very minimum. Also the split valence orbital population of $F$ atoms suggested $F 1$ and $F_{2}$ as having higher gross orbital population (GOP) compared to $\mathrm{F}_{3}$ and $\mathrm{F}_{4}$ (IV e).

The higher total charge of the first two $\mathrm{F}$ atoms compared to the rest of the two may be because of the combined effect of negative hyperconjugation (higher) and the inductive effect (lower) which is absent in the rest of the fluorine atoms $3 \& 4$ as they lie in the plane of the ring i.e. $90^{\circ}$ to the $\pi$ orbital of the carbon atom in the ring when the negative hyperconjugation effect falls to zero. When in plane, the F atoms $3 \& 4$ might be showing higher inductive effect compared to $\mathrm{F}$ atoms $1 \& 2$. The inductive effects can be guessed from the $\sigma$ or the total charges as they are operative only through the $\sigma$ bonds, but since there is a hypervalent atom the anomeric effect predominates, which is supported by the gross orbital population $^{8}$ (GOP), as in Table 2.

It was also found that all the four fluorine atoms, upon optimization tend to lie nearly in plane. Optimization without symmetry enforcement resulted in the two fluorine atoms 1 \& 2 at the apex of the trigonal bipyramidal geometry IV c (in accordance with Bent's rule) ${ }^{9}$. After optimisation it was found that the $\mathrm{F}$ atoms have moved away from the ring by a few degrees, resulting in larger $\mathrm{P}-\mathrm{F}$ bond length. This lengthening should have been caused by the inflow of more electrons by both effects and hence the increased total charge. 
The magnitude of bond lengthening was also compared with the systems I and IV and it was found that the more the number of $\mathrm{F}$ atoms, the greater was the increase in the bond length of the $\mathrm{C}-\mathrm{X}$. This was also proportional with the decrease in the $\mathrm{A}-\mathrm{Y}$ bond lengths when moving from three $\mathrm{F}$ atoms in $\mathbf{I}$ to four $\mathrm{F}$ atoms in IV.

\section{Phenylpentafluorosulphorane}

The structure $\mathrm{C}_{6} \mathrm{H}_{5} \mathrm{SF}_{5}$ was studied at the same level. During the optimisation the molecule was allowed to rotate freely along the $\mathrm{C}-\mathrm{S}-\mathrm{F}$ axis (VI b) under the $\mathrm{C}_{2 \mathrm{~V}}$ symmetry. The molecule assumed VI a orientation and this structure was found to be stable. The bond length and charge calculations are presented in Table 1 and 2 respectively. The theoretical bond length value for the $\mathrm{S}-\mathrm{F}$ was found to be $1.59 \mathrm{~A}^{\circ}$.

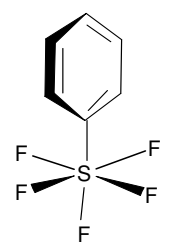

VI a (Cs)

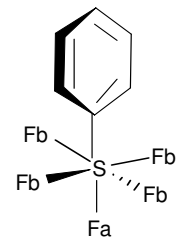

VI b $\left(\mathbf{C}_{2 \mathrm{v}}\right)$

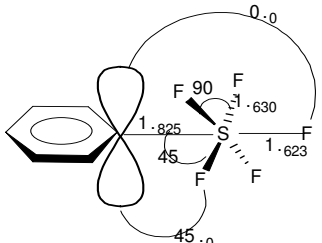

VI c

Structures of Phenylpentafluorosulphorane under different symmetries (VI a \& b) and the bond lengths and angle under Anomeric effect

In this system the $\pi$ charge on the apex $F_{a}$-atom (opposite to the phenyl ring in an octahedral geometry) was found to increase in support of negative hyperconjugation, but two of the geometrical information viz. the bond length and the bond angle, did not support this. The $\mathrm{S}-\mathrm{F}$ bond length should have increased (compared to other $\mathrm{F}$ atoms), but it had a reduced value. At the same time a bond angle (ipso C-S-F $\mathrm{F}_{\mathrm{a}}$ ) of $180^{\circ}$ meant a dihedral angle of $90^{\circ}$ with $\pi$ orbital of the ipso C-atom-C-S-F, where the negative hyperconjugation effect is either zero or most minimum. Hence the only effect possible with this F-atom was the inductive effect. This was evident from the sigma charges present on the ipso $\mathrm{C}$-atom, which is the highest value in the table 2 . The overall effect was supported by a decreased $\mathrm{C}-\mathrm{S}$ bond length ${ }^{10}$.

For $\mathrm{F}$ atom that is responsible for negative hyperconjugation the value of gross orbital population should have been higher compared with other $\mathrm{F}$ atoms in the same molecule. All other $\mathrm{F}$ atoms which are at 90 degrees to the phenyl ring having a favourable dihedral angle for overlap with $p i$ orbital should show negative hyperconjugation. In this case the dihedral angle between pi of ipso C-C-P-F $\mathrm{F}_{\mathrm{b}}$ was 45 degree (VI c), which is just a minimum for a favourable overlap to give anomeric effect. Hence the effect is less marked compared to the inductive effect.

\section{Conclusion}

Negative hyperconjugation is found in the systems having hypervalent atoms attached to highly electronegative atoms and $\pi$ systems in a geometrically anti-periplanar structure. This effect is found along with the inductive effect and can be differentiated in atoms having different geometry in the same system. By this way some atoms have high "anomeric effect", while some just show "inductive effect". Geometry of the system and the charges on the electronegative and the ipso atoms through which the $\pi$ systems are attached are the helpful factors for establishing negative hyperconjugation. This is because the anomeric 
effect is maximum when the $\pi$ orbital, C- atom, Hypervalent atom and the electronegative atom have a dihedral angle of either 0 degree or 180 degrees (antiperiplanar, in this sense). Equally important is the inductive effect, which is operative through the sigma bonds. The charges both on the $\sigma$ and $\pi$ orbitals help in evaluating the types of effect. Of the three systems of interest studied, viz., $\mathrm{C}_{6} \mathrm{H}_{5}-\mathrm{A}$, where $\mathrm{A}=\mathrm{SiF}_{3}, \mathrm{PF}_{4}$ and $\mathrm{SF}_{5}$, the last system showed less anomeric effect compared with the former two. In the last system, the inductive effect was competing with the anomeric effect. Wherever necessary the imaginary systems should be employed to study and compare the effects ${ }^{11}$.

The overall effects should thus be calculated specifically for each system and with hypervalent atoms and electronegative atoms the effect was significant.

\section{Acknowledgement}

One of the authors PKMI is thankful to Dr SCN, Dean of Organic Chemistry and RSIC, Indian Institute of Science, Bangalore for permitting this work. The award of Young Scientist Fellowship by the Tamil Nadu State Council for Science and Technology is gratefully acknowledged.

\section{References}

1. IUPAC Recommendations, Pure \& Applied Chem., 1999, 71, (10), 1919-1981. (http://www.iupac.org/reports/1999/7110minkin/n.html)

2. $\quad$ Schleyer P R and Kos A J, Tetrahedron, 1983, 39 (7), 1141-50.

3. Hehre W J, L Radom, PvR Schleyer and Pople J A, Ab Initio MO Theory, Wiley Publications, NY, 1992.

4. $\quad$ Pople J A and Gordon, J. Am. Chem. Soc. 1987, 89, 42-53.

5. Tim Clark, Handbook of Computational Chemistry, Wiley Eastern Publications, New York, 1999, pp.120.

6. Alan E Reed and Paul von Rague Schleyer, J. Am. Chem. Soc., 1990, 112(4), 1436.

7. King J F, Rathore R, Guo Z, Li M and Payne N C, J. Am. Chem. Soc., 2000, 122, 10308-10324.

8. Kormos B L and Cramer C, J. Inorg. Chem., 2003. 42, 6691.

9. Murugavel R, Krishnamurthy S S and Nethaji M, J. Chem. Soc., Dalton Trans., 1993 3635-3639.

10. Tamejiro H, Organofluorine Compounds: Chemistry and Applications, SpringerVerlag, Berlin, 2000, 1-22.

11. Murphy E F, Murugavel R and Roesky H W, Chem. Rev., 1997, 97, 3425-3468. 


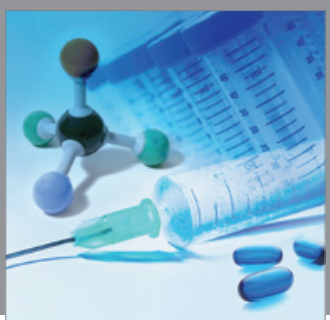

International Journal of

Medicinal Chemistry

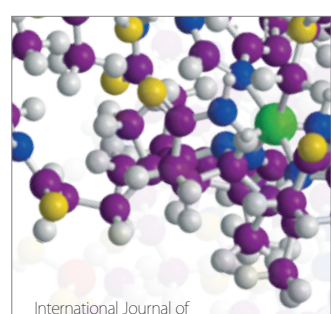

Carbohydrate Chemistry

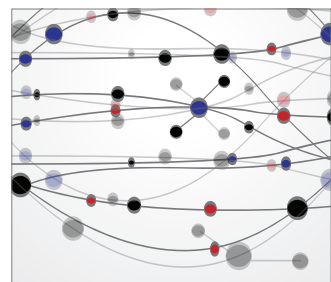

The Scientific World Journal
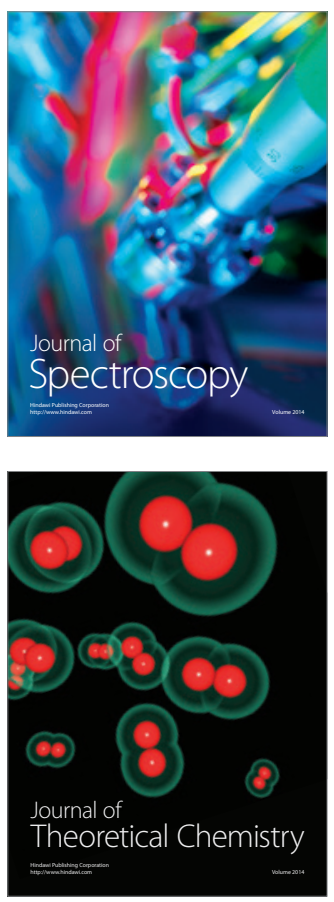
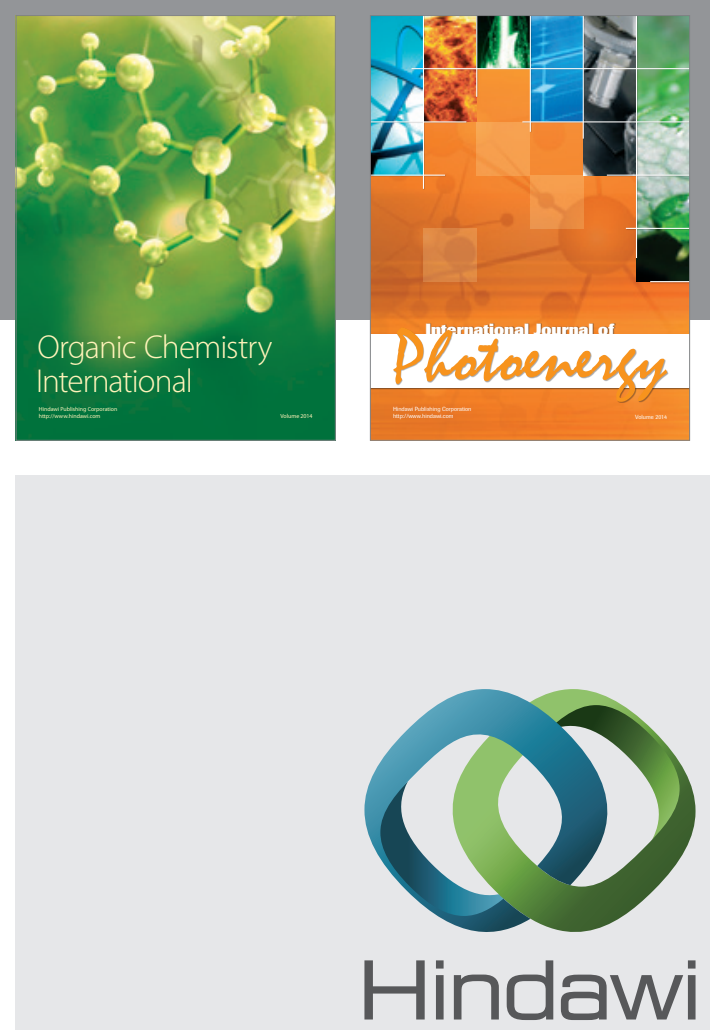

Submit your manuscripts at

http://www.hindawi.com
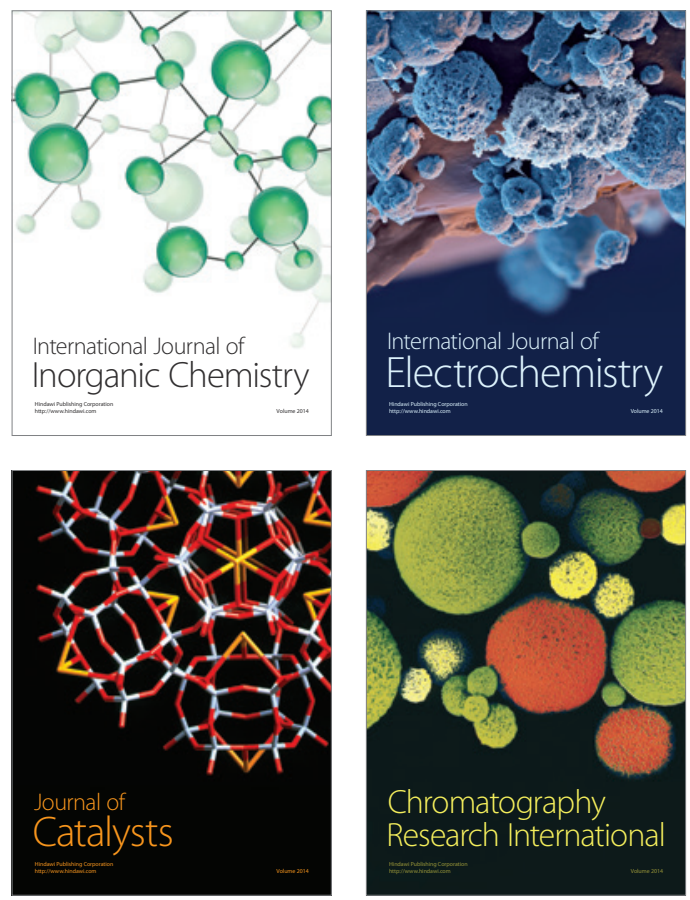
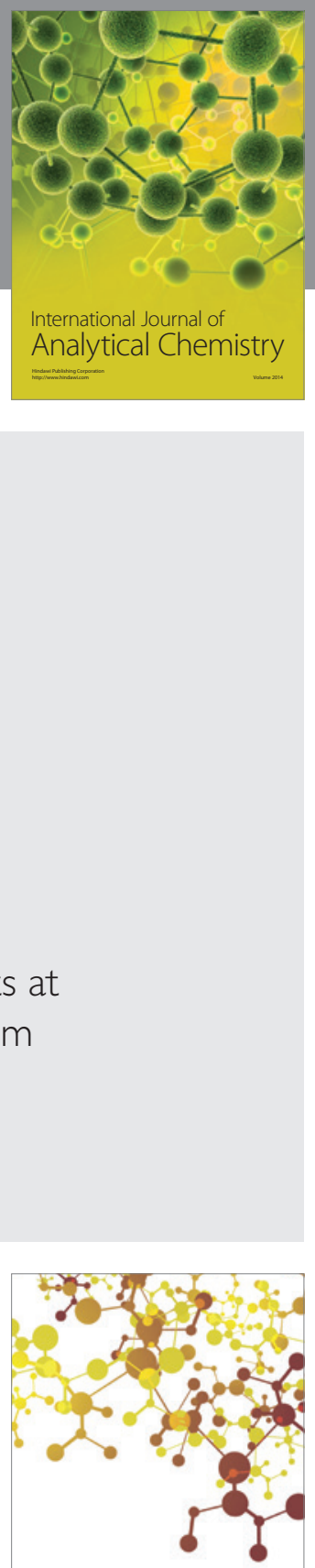

Journal of

Applied Chemistry
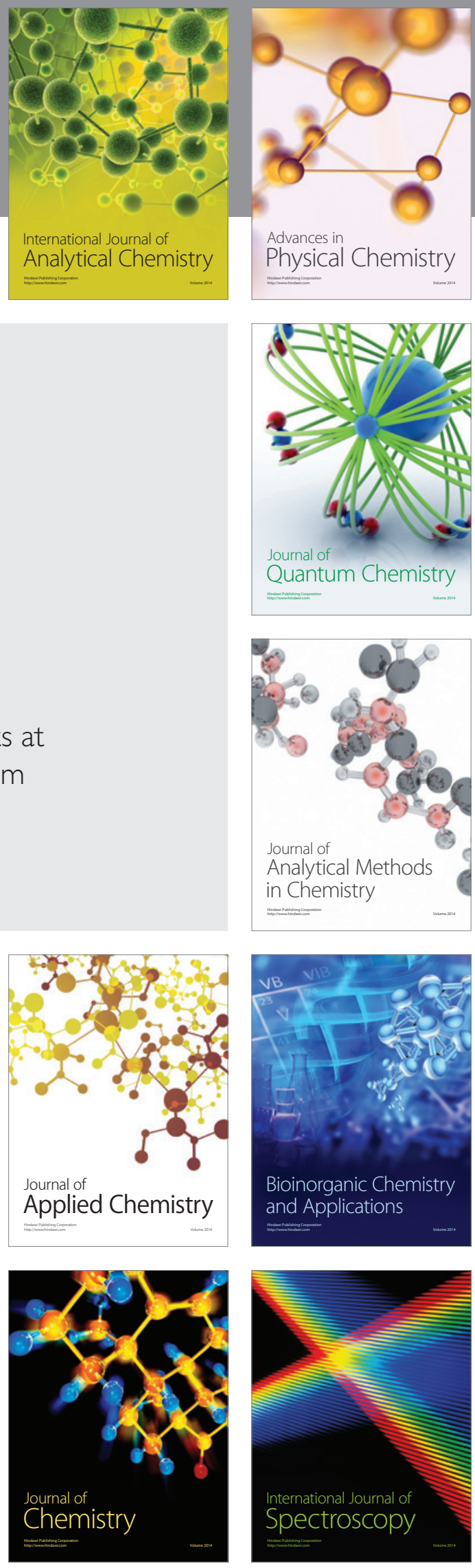